\title{
Expanded/Activated Gamma Delta T-cells
}

National Cancer Institute

\section{Source}

National Cancer Institute. Expanded/Activated Gamma Delta T-cells. NCI Thesaurus. Code C157634.

A preparation of gamma delta T-lymphocytes derived from donor T-cells that have been expanded and activated ex-vivo and further depleted of alpha and beta T-cell receptors (TCRs), with potential immunomodulating and antineoplastic activities. Upon administration, these expanded/activated gamma delta (EAGD) T-cells secrete interferon-gamma (IFN-g) and exert direct killing of tumor cells. In addition, these cells activate the immune system to exert a cytotoxic T-lymphocyte $(C T L)$ response against tumor cells. Gamma delta T-lymphocytes play a key role in the activation of the immune system and do not require major histocompatibility complex (MHC)-mediated antigen presentation to exert their cytotoxic effect. 